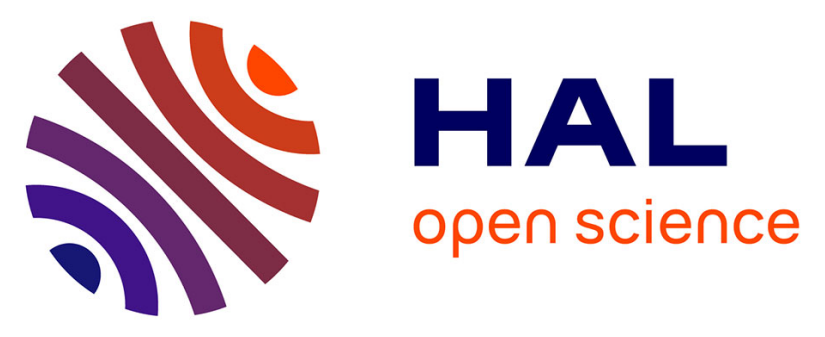

\title{
Biological Crystallography Interactions of a new a-aminophosphinic derivative inside the active site of TLN (thermolysin): a model for zinc-metalloendopeptidase inhibition
}

Mohamed Selkti, Alain Tomas, Jean-François Gaucher, Thierry Prangé, Marie-Claude Fournié-Zaluski, Huixiong Chen, Bernard-Pierre Roques

\section{To cite this version:}

Mohamed Selkti, Alain Tomas, Jean-François Gaucher, Thierry Prangé, Marie-Claude FourniéZaluski, et al.. Biological Crystallography Interactions of a new a-aminophosphinic derivative inside the active site of TLN (thermolysin): a model for zinc-metalloendopeptidase inhibition. Acta crystallographica Section D : Structural biology [1993-..], 2003, 10.1107/S0907444903010060 . hal-02880618

\section{HAL Id: hal-02880618 https://hal.science/hal-02880618}

Submitted on 25 Jun 2020

HAL is a multi-disciplinary open access archive for the deposit and dissemination of scientific research documents, whether they are published or not. The documents may come from teaching and research institutions in France or abroad, or from public or private research centers.
L'archive ouverte pluridisciplinaire HAL, est destinée au dépôt et à la diffusion de documents scientifiques de niveau recherche, publiés ou non, émanant des établissements d'enseignement et de recherche français ou étrangers, des laboratoires publics ou privés. 
Acta Crystallographica Section D

Biological

Crystallography

ISSN 0907-4449

\section{Interactions of a new $a$-aminophosphinic derivative inside the active site of TLN (thermolysin): a model for zinc-metalloendopeptidase inhibition}

Mohamed Selkti, ${ }^{a *}$ Alain Tomas, ${ }^{a}$ Jean-François Gaucher, ${ }^{a}$ Thierry Prangé, a,b Marie-Claude FourniéZaluski, ${ }^{\mathrm{c}}$ Huixiong Chen ${ }^{\mathrm{c}}$ and Bernard-Pierre Roques ${ }^{c}$

aLaboratoire de Cristallographie et RMN Biologiques (UMR 8015 CNRS), 4 Avenue de I'Observatoire, 75270 Paris CEDEX 06, France, bLURE, Bâtiment 209d, Université Paris-Sud, 91405 Orsay CEDEX, France, and ${ }^{\mathbf{C}}$ Département de Pharmacochimie Moléculaire et Structurale (INSERM U266-CNRS FRE 2463), 4 Avenue de I'Observatoire, 75270 Paris CEDEX 06, France

Correspondence e-mail:

selkti@pharmacie.univ-paris5.fr
(C) 2003 International Union of Crystallography Printed in Denmark - all rights reserved
A new $\alpha$-aminophosphinic compound able to inhibit both zinc-containing exopeptidases and endopeptidases has been crystallized with TLN as a model in order to investigate the mode of zinc recognition by the phosphinic moiety and to evaluate the potential role of the free $\alpha$-amino group in the formation of enzyme-inhibitor complexes. In addition to the main interactions between the backbone of the inhibitor and the enzyme active site, it is observed that the phosphinic group acts as a distorted bidentate ligand for the zinc ion, while the free $\alpha$-amino function does not directly participate in interactions within the active site. Association of the present data and the $K_{i}$ values of various analogues of the inhibitor towards TLN and neprilysin suggests differences in the hydrophobicity of the $\mathrm{S}_{1}-\mathrm{S}_{2}$ domains of the enzymes. This could be taken into account in the design of selective inhibitors.

\section{Introduction}

Thermolysin (TLN; EC 3.4.24.28), a thermostable bacterial protease isolated from Bacillus thermoproteolyticus, is considered to be the prototype of zinc metalloproteases belonging to the gluzincin family (MA clan). Indeed, crystallographic analysis of a number of TLN-inhibitor complexes (Matthews, 1988) has allowed an understanding of the mode of binding of these inhibitors and allowed the mechanism of action of these peptidases to be determined (Hangauer et al., 1984; Matthews, 1988). In addition, these mechanistic and structural parameters were extended to other related zinc metallopeptidases, such as the angiotensinconverting enzyme (ACE; EC 3.4.15.1; Bohacek et al., 1996), the endothelin-converting enzyme (ECE; Sansom et al., 1998) and neprilysin (NEP; EC 3.4.24.11; Tiraboschi et al., 1999), the three-dimensional structures of which were unknown at the time. The validity of this approach has recently been confirmed by X-ray analyses of neprilysin (Oefner et al., 2000), human leucotriene $\mathrm{A}_{4}$ hydrolase $\left(\mathrm{LTA}_{4} \mathrm{H}\right.$; Thunnissen et al., 2001) and angiotensin-converting enzyme (Natesh et al., 2003). These analyses demonstrated that the three-dimensional structures of the active sites are quite similar to that of TLN. Additional crystallographic studies of other zinc metallopeptidases belonging to other families, such as matrix metallopeptidases (Bode et al., 1993) and botulinum neurotoxins (Swaminathan \& Eswaramoorthy, 2000; Hanson \& Stevens, 2000), have also shown that most of the structural characteristics of the TLN catalytic site are preserved in these enzymes.

Since the discovery that phosphoramidon (Umezawa et al., $1972)$ is able to competitively interact with TLN $\left(K_{i}=2.8 \times\right.$ $10^{-8} M$; Komiyama et al., 1975), a number of phosphorus-
Received 13 February 2003 Accepted 7 May 2003

PDB Reference: thermolysin$\alpha$-aminophosphinic compound complex, 1os0, r1os0sf. 
containing peptide analogues have been developed as potent zinc-metallopeptidase inhibitors (Kam et al., 1979; Bartlett \& Marlowe, 1983, 1987). Owing to the presence of a tetrahedral $\mathrm{P}$ atom in these compounds, it has been suggested that phosphonates, phosphonamidates or phosphinates could mimic the transition state of peptide-substrate hydrolysis. To confirm this hypothesis, a number of phosphonates and phosphonamidates

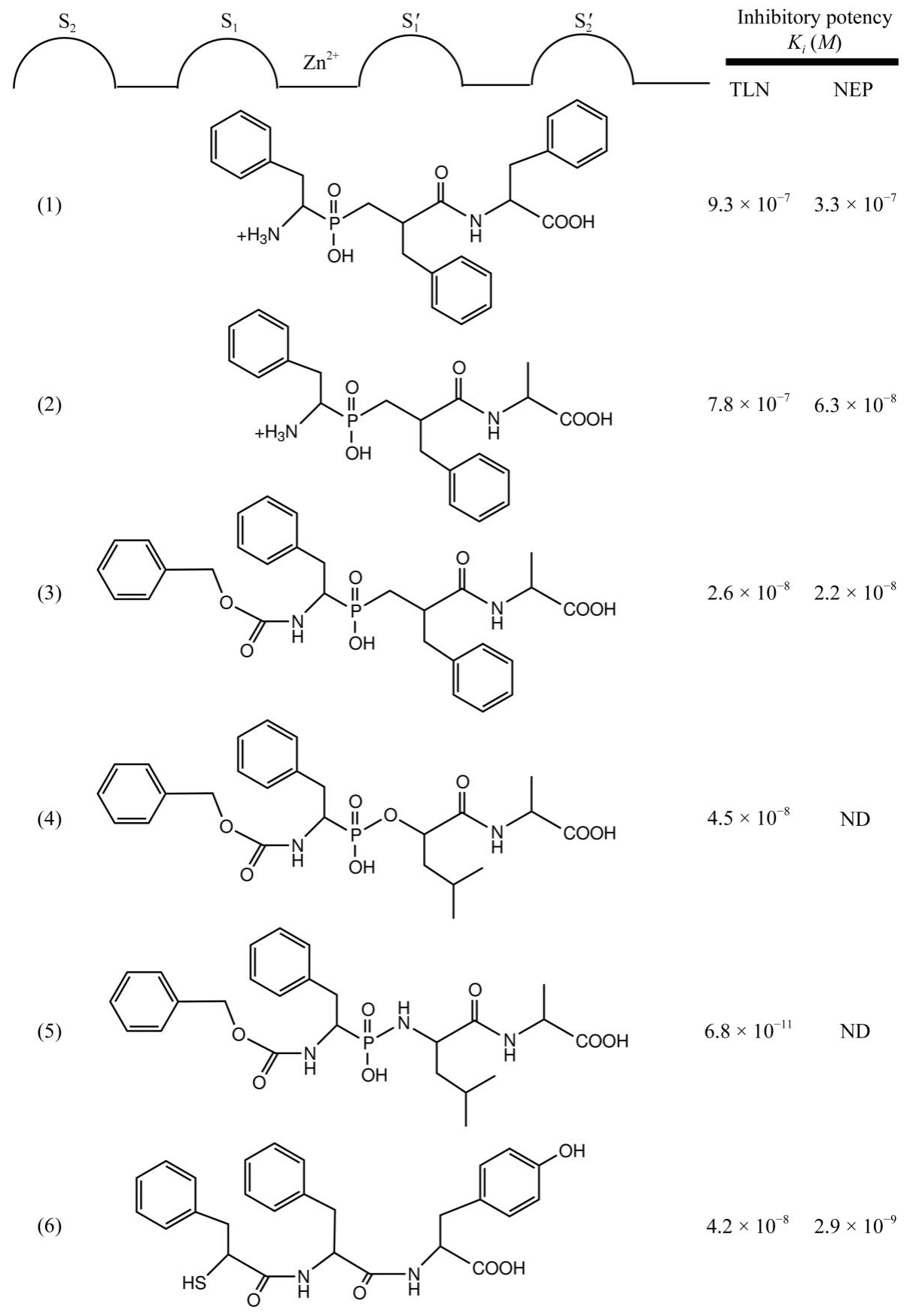

Figure 1

Schematic representation of the four subsites in $\mathrm{Zn}$ metallopeptidases according to Schechter \& Berger (1967) and the formulae of the six designed inhibitors mentioned in the text, together with their corresponding $K_{i}$ inhibition constants for TLN and NEP. (1), (2) and (3) are the new phosphinic inhibitors. (1) and (2) differ in the C-terminal peptide (Phe or Ala), while (3) is the $N$-protected derivative of (2). Values for (4) and (5) are from Bartlett \& Marlowe (1987) and those for (6) are from Gaucher et al. (1999). were co-crystallized with TLN (Weaver et al., 1977; Tronrud et al., 1986, 1987; Holden et al., 1987). In all cases it was observed that at least one oxygen of the phosphoryl group binds directly to the $\mathrm{Zn}^{2+}$, while the second oxygen remains in the vicinity of the catalytic glutamate Glu143. Furthermore, both monodentation and bidentation of the zinc ion by $\mathrm{O}$ atom(s) of the phosphoryl moiety are observed, depending on the inhibitor structure. Thus, (i) in the TLN-phosphoramidon complex only one oxygen binds $\mathrm{Zn}^{2+}$, leading to tetracoordination (Weaver et al., 1977), (ii) in the complex with $\mathrm{ZF}^{\mathrm{P}} \mathrm{LA}$ (Holden et al., 1987), $\mathrm{Zn}^{2+}$ is pentacoordinated owing to bidentation by the two phosphonamide $\mathrm{O}$ atoms and (iii) with the small molecule P-Leu- $\mathrm{NH}_{2}$ (Tronrud et al., 1986) the structure is intermediate between these two modes of binding.

It is interesting to observe that the bidentation of zinc results in a significant increase in inhibitory potencies. Until now, the $\mathrm{ZF}^{\mathrm{P}} \mathrm{LA}$ molecule represented the most efficient inhibitor of TLN, with a $K_{i}$ of $6.7 \times 10^{-11} M$ (Bartlett \& Marlowe, 1987).

In the search for potent dual inhibitors of both the endopeptidase neprilysin (NEP) and the exopeptidase aminopeptidase N (APN; EC 3.4.11.2) for use as potential analgesics (Chen et al., 1998, 2000), we have developed a number of $\alpha$-aminophosphinic derivatives with the general formula ${ }^{+} \mathrm{H}_{3} \mathrm{~N}$ $\mathrm{CH}\left(R_{1}\right) \mathrm{P}(\mathrm{O})(\mathrm{OH}) \mathrm{CH}_{2} \mathrm{CH}\left(R_{1}^{\prime}\right) \mathrm{CONH}-$ $\mathrm{CH}\left(R_{2}^{\prime}\right)-\mathrm{COOH}$ with $R_{1}, R_{1}^{\prime}$ and $R_{2}^{\prime}$ suitably designed (Fig. 1). These molecules have low-nanomolar affinities for both NEP and APN enzymes.

To understand these results in terms of endopeptidase versus exopeptidase recognition, two questions are addressed. (i) Does the phosphinic group act a monodentate or a bidentate ligand for the zinc as observed in the mercapto inhibitor (6)? (ii) Does the free $\alpha$-amino group of the inhibitor play a role in NEP recognition?

To answer to these questions, the inhibitor (1) (Fig. 1), which is assumed to recognize the three $S_{1}, S_{1}^{\prime}$ and $S_{2}^{\prime}$ subsites (Schechter \& Berger, 1967) of the enzymes, has been crystallized with TLN as a model for NEP (Tiraboschi et al., 1999; Oefner et al., 2000). As shown in Fig. 1, NEP $\left(K_{i}=3.3 \times 10^{-7} M\right)$ and TLN $\left(K_{i}=9.3 \times 10^{-7} M\right)$ have similar affinities towards compound (1). 


\section{Materials and methods}

\subsection{Chemicals}

The inhibitors were synthesized in the laboratory according to Chen et al. (2000). Thermolysin was purchased from Sigma (France). Neutral endopeptidase (NEP) was obtained from rabbit kidney and purified to homogeneity as described previously (Aubry et al., 1987).

\subsection{Biochemical assays}

Inhibitory potencies were determined using $\left({ }^{3} \mathrm{H}\right) \mathrm{Tyr}-\mathrm{Gly}-$ Gly-Phe-Leu $\left(K_{\mathrm{M}}=2 \mu M\right.$; Benchetrit et al., 1987) as the substrate for TLN and dansyl-D-Ala- $\left(\mathrm{pNO}_{2}\right)$ Phe-Gly $\left(K_{\mathrm{M}}=\right.$ $37 \mu M$ ) as the substrate for NEP (Goudreau et al., 1994).

Accounting for their competitive nature, the $K_{i}$ values of inhibitors were determined from their $\mathrm{IC}_{50}$ values using the Chen-Prussoff relation $\left[K_{i}=\mathrm{IC}_{50} /\left(1+S / K_{\mathrm{M}}\right)\right]$.

\subsection{Crystallization}

TLN was co-crystallized with inhibitor (1) using the hanging-drop method following previously described procedures (Matthews et al., 1972; Gaucher et al., 1999). Prior to crystallization, added salts were removed from TLN by suspending $13 \mathrm{mg}$ lyophilized TLN in $0.7 \mathrm{ml}$ water followed by centrifugation at $7400 \mathrm{~g}$. The pellet was dissolved in $100 \mu \mathrm{l}$ of solution $A[50 \mathrm{~m} M$ Tris acetate buffer $\mathrm{pH}$ 8.0, 0.5 $M$ calcium acetate, $4 \mathrm{~m} M$ dithiothreitol, $1 \mathrm{~m} M$ sodium azide and $45 \%(v / v)$ dimethylsulfoxide (DMSO)]. Enzyme concentrations were estimated using an $\varepsilon_{280}$ of $56000 \mathrm{M}^{-1} \mathrm{~cm}^{-1} .1 \mu \mathrm{l}$ drops containing TLN (120 mg ml $\mathrm{mg}^{-1}$ or $3.2 \mathrm{mM}$ TLN) and $20 \mathrm{~m} M$ inhibitor (1) in solution $A$ were mixed and equilibrated against a $1 \mathrm{ml}$ reservoir containing $520 \mu \mathrm{l}$ solution $A$ and $480 \mu \mathrm{l}$ water. Hexagonal crystals grew in about one to two months at $278 \mathrm{~K}$.

\subsection{Data collections}

Diffraction data were recorded at $277 \mathrm{~K}$ at the LURE synchrotron facility, Orsay, France. The wavelength was set to $0.962 \AA$. The crystals were mounted in wet capillaries, usually with the $c$ axis misaligned by about $20^{\circ}$ with respect to the rotation spindle, in order to minimize loss of data from the 'blind region'. A single crystal was used and 50 frames with a rotation angle of $1^{\circ}$ each were collected using a $300 \mathrm{~mm}$ diameter MAR Research image-plate system connected to the W32 beamline (Fourme et al., 1992). The crystal-to-detector distance was set to $250 \mathrm{~mm}$. Frames were processed with the MOSFLM program (Leslie, 1990) and merged and scaled with SCALA; amplitudes were calculated with TRUNCATE (Collaborative Computational Project, Number 4, 1994). Table 1 summarizes the results of the data processing.

\subsection{Structure solution and refinement}

Refinement was carried out by alternate cycles of CNS calculation (Brünger et al., 1990) and manual fitting of the model into electron-density maps using $O$ (Jones et al., 1991). $10 \%$ of the data were used for cross-validation of the refine-
Table 1

Data-collection and refinement statistics for the TLN-inhibitor (1) complex.

\begin{tabular}{|c|c|}
\hline \multicolumn{2}{|l|}{ Data collection } \\
\hline Space group & $P 6_{1} 22$ \\
\hline \multicolumn{2}{|l|}{ Unit-cell parameters $(\AA)$} \\
\hline$a=b$ & 93.78 \\
\hline$c$ & 132.25 \\
\hline No. of unique reflections & 23742 \\
\hline Data redundancy & 5.2 \\
\hline \multicolumn{2}{|l|}{ All data $(19.9-2.0 \AA)$} \\
\hline$R_{\mathrm{sym}}(\%)$ & 7.6 \\
\hline Mean $I / \sigma(I)$ & 16.3 \\
\hline Completeness $(\%)$ & 91.6 \\
\hline \multicolumn{2}{|l|}{ Highest resolution shell $(2.1-2.0 \AA ̊)$} \\
\hline$R_{\text {sym }}(\%)$ & 12.5 \\
\hline Mean $I / \sigma(I)$ & 7.4 \\
\hline Completeness $(\%)$ & 85.5 \\
\hline \multicolumn{2}{|l|}{ Refinement $(S H E L X L)$} \\
\hline \multicolumn{2}{|l|}{ No. of atoms } \\
\hline TLN & 2432 \\
\hline Inhibitor & 35 \\
\hline DMSO, $\mathrm{Ca}^{2+}, \mathrm{Zn}^{2+}$ & $1,4,1$ \\
\hline Solvent & 186 \\
\hline Resolution range $(\AA)$ & $19.0-2.0$ \\
\hline No. of parameters/restraints & $10666 / 10251$ \\
\hline$R$ factor (\%) for $4 \sigma$ observed data (No. of data) & 13.9 (19094) \\
\hline$R$ factor (\%) for all data (No. of data) & $14.6(21413)$ \\
\hline Free $R$ factor (\%) for $6 \%$ of observed data (No. of data) & $17.3(1903)$ \\
\hline \multicolumn{2}{|l|}{ R.m.s. deviations (No.) } \\
\hline 1-2 Bond length $(\AA ̊)$ & $0.021(2531)$ \\
\hline $1-3$ Bond-distance angles $(\AA)$ & $0.022(3447)$ \\
\hline Planes $(\AA)$ & $0.27(891)$ \\
\hline Non-zero chiral volumes $\left(\AA^{3}\right)$ & $0.049(364)$ \\
\hline Zero chiral volumes $\left(\AA^{3}\right)$ & $0.028(401)$ \\
\hline \multicolumn{2}{|l|}{ Mean isotropic $\langle B\rangle$ values $\left(\AA^{2}\right)$} \\
\hline Main chain & 11.1 \\
\hline Side chain & 16.9 \\
\hline Water molecules & 31.4 \\
\hline Inhibitor & 25.2 \\
\hline Residuals in final Fourier $\operatorname{map}(\min / \max )\left(\mathrm{e}^{-}\right)$ & $-0.25 /+0.40$ \\
\hline
\end{tabular}

ment (the $R_{\text {free }}$ value). A maximum-likelihood target was used in refinements and a bulk-solvent correction with anisotropic $B$ factor was applied to low-resolution data.

The crystals used in this study were isomorphous to native TLN. The structure of the native TLN solved at room temperature (PDB code 1lnf) was used as the starting model. The complexed dipeptide Val-Lys and all solvent molecules were removed and an overall $B$ factor of $16 \AA^{2}$ was assigned to all atoms. The refinement began with rigid-body least-squares fitting, followed by refinement of the atomic positions by energy minimization at an initial resolution of $2.5 \AA$. The resolution was progressively increased to the maximum of $2.0 \AA$.

The model was subjected to cycles of positional refinement and restrained isotropic atomic temperature-factor refinement. After each cycle of $B$-factor refinement, the model was examined on the graphics system and refitted to the density. Water molecules were added to the model using WATERPICK (in $C N S$ ). They were placed at the positions of large positive $(>2 \sigma)$ peaks in difference Fourier maps provided that they were also present in the $2 F_{o}-F_{c}$ maps with a suitable hydrogen-bonding environment.

During the course of water localization, electron-density maps clearly showed the position of the ligand (inhibitor) in 
the active site (Fig. 2). The phosphonamidate inhibitor $\mathrm{ZF}^{\mathrm{P}} \mathrm{LA}$ (Holden et al., 1987) was used as a template for building a model for the phosphinic inhibitor (1). The model was then fitted to the electron-density map and included in structurefactor calculations during subsequent refinements.
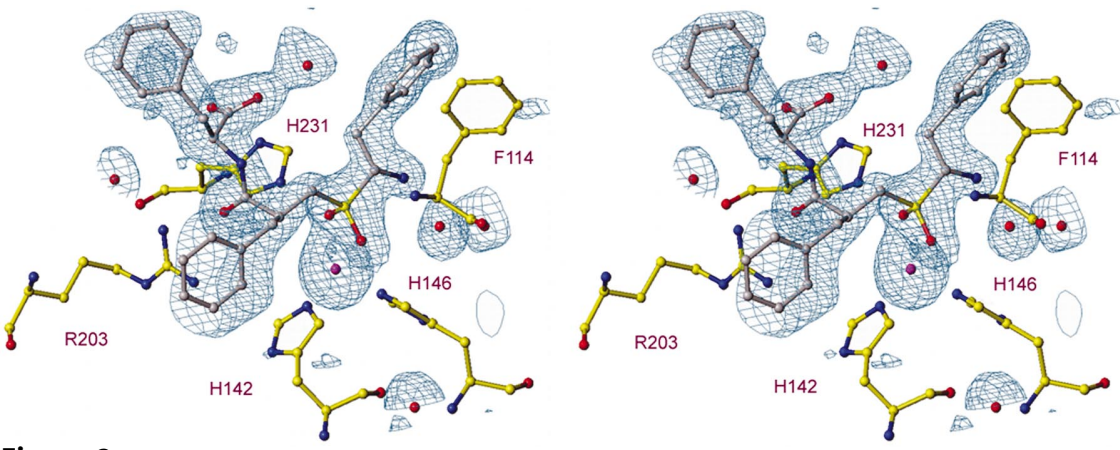

Figure 2

An omit map around the $\mathrm{Zn}$ atom calculated at the end of the water-localization steps, before introducing the inhibitor into the structure-factor calculations. The electron density is superimposed on the final refined model of inhibitor (1) (map contouring is $2 \sigma$ above the mean).
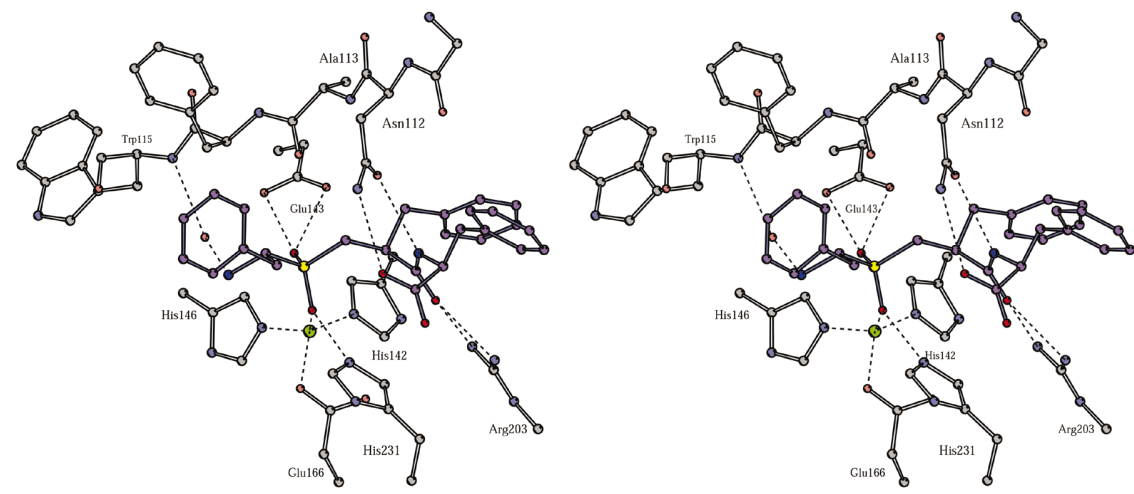

Figure 3

Stereoscopic view of the interactions between the phosphinic inhibitor (1) and TLN in the crystal. Polar bonds are dashed.

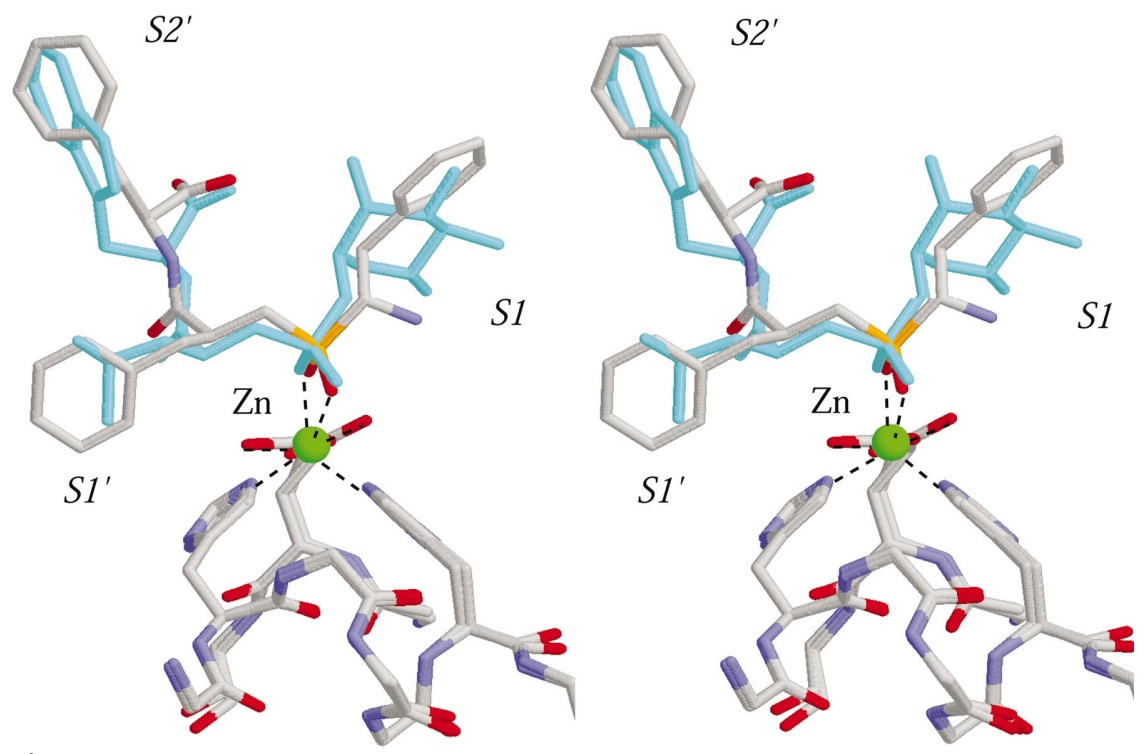

Figure 4

The NEP (Oefner et al., 2000) and TLN active sites superimposed using a $L S Q$ fit of their sequences $X-\mathrm{H}-X_{3}-\mathrm{H}-X$ and $X$-Q- $X$ residues, plus the $\mathrm{Zn}$ atom. The two inhibitors (1) for TLN and phosphoramidon for NEP (in plain blue) are shown in their bound states: stereoscopic view, RASMOL program (Merritt \& Bacon, 1997).
In the final stages of the refinement, an important residual molecule because of the absence of putative hydrogen bonding in a hydrophobic environment and because of its broad density shape remained. Although individual atomic positions cannot be distinguished, this density was best modelled as a DMSO molecule. In the last step, the structure was refined against all data $\left(R_{\text {free }}=17.0 \%\right.$ before merging the free set) using the SHELXL program (Sheldrick \& Schneider, 1997). The refinement statistics are given in Table 1.

\section{Results}

\subsection{Quality of the model}

The final model consists of 2432 protein atoms, 35 inhibitor atoms, 186 molecules of water and one DMSO moiety plus one zinc and four calcium ions. The structural model is of good quality as indicated by the PROCHECK analysis (Laskowski et al., 1993), by the low crystallographic validation statistics (Table 1) and by the small mean deviations of the geometrical parameters from their ideal values. The final $R$ factor is $13.9 \%$ for the resolution range $10-2.0 \AA$. The root-mean-square (r.m.s.) coordinate error was estimated to be $0.16 \AA$ from a Luzzati plot (Luzzati, 1952).

\subsection{Zinc-binding site}

The distances between the zinc ion and the two $\mathrm{O}$ atoms of the phosphinic moiety are $1.90 \AA$ (PO1) and $2.90 \AA \quad$ (PO2) (Table 2), indicating that they are both ligands of the zinc, although the coordination of the second oxygen is considerably weaker than that of the first. An equivalent situation was also observed by Tronrud et al. (1986) in the TLN-P-Leu-NH $\mathrm{NH}_{2}$ complex (PO1 = $2.1 \AA$, PO2 = $2.8 \AA$ ). This leads to a structure with a zinc coordination that is intermediate between tetrahedral and a distorted trigonal bipyramid (Table 2). In addition to PO1 and PO2, three residues of TLN are bonded to the zinc ion: His146 NE2, His142 NE2 and Glu166 OE2 (Fig. 3).

\subsection{Stabilization of the transition state}

In the transition state of the hydrolysis, the carboxyanion formed by water attack on the carbonyl group is expected to be stabilized by various hydrogen bonds 
involving either the catalytic Glu143 or His231 or Tyr157 (Matthews, 1988). In the crystal structure of inhibitor (1), the short distances between phosphinic $\mathrm{O}$ atoms and these three residues reflect this network of hydrogen bonds: the two $\mathrm{O}$ atoms of Glu143 are 2.71 and $2.86 \AA$ from PO2 and the PO1 atom is located $2.88 \AA$ from the imidazole nitrogen NE2 of His 231 but at $3.2 \AA$ from the phenolic hydroxyl group of Tyr157.

\subsection{Binding subsites}

As expected, the three aromatic side chains $\left(R_{1}, R_{1}^{\prime}\right.$ and $\left.R_{2}^{\prime}\right)$ in inhibitor (1) fit the $S_{1}, S_{1}^{\prime}$ and $S_{2}^{\prime}$ subsites of the enzyme. The $S_{1}$ and $S_{2}^{\prime}$ subsites are open and accessible to the solvent and are not well defined. $S_{1}^{\prime}$ is a deep hydrophobic cavity which is particularly well suited to the $R_{1}^{\prime}$ side chain of the inhibitor. This is illustrated by the low thermal parameters of the $R_{1}^{\prime}$ ring $\left(13.3 \AA^{2}\right.$ ) compared with the other aromatic side chains (mean $\langle B\rangle$ factors are 28.2 and $29.3 \AA^{2}$ for $R_{1}$ and $R_{2}^{\prime}$, respectively).

At the N-terminus of the inhibitor, the only interaction that connects this part to the $S_{1}$ subsite is the water molecule W470, which forms a bridge between the free amino group of the inhibitor and the amide group of Trp115. Although this water molecule is distant from the $\mathrm{Zn}$ atom $(4.7 \AA)$, it appears to play a central role as it also stays in the vicinity of $\mathrm{O} 2 \mathrm{P}$ of the inhibitor $(d=2.91 \AA)$ and Glu143 O1E $(d=3.0 \AA) . R_{1}$ (the phenyl ring) is essentially free. At the same time, the $R_{1}^{\prime}$ and $R_{2}^{\prime}$ side chains are stabilized by a set of hydrogen bonds within their respective subsites: the carbonyl oxygen of $R_{1}^{\prime}$ is hydrogen bonded to both the NH1 atom $(2.69 \AA)$ and the NH2 atom (2.91 $\AA$ ) of Arg203, while the Phe moiety of the inhibitor (the C-terminus) interacts through two weak hydrogen bonds with Asn112: $d$ (Phe NH-Asn112 OD1) = $3.19 \AA$ and $d($ Phe O-Asn112 ND2) = 3.09 $\AA$. The carboxylate group of the inhibitor is also bound to two water molecules (W493 and W586).

\section{Discussion}

The three-dimensional structure of the TLN-compound (1) complex obtained in this study shows that the essential interactions stabilizing an inhibitor in the active site of this enzyme are satisfied, at least at the level of the catalytic site and its 'prime' domain. In contrast, recognition of the $S_{1}$ subsite ('non-prime' domain) by the N-terminal benzylic moiety of inhibitor (1) is less important as expected.

It has previously been shown by crystallization of the phosphonamidate inhibitor $\mathrm{ZF}^{\mathrm{P}} \mathrm{LA}$ (Holden et al., 1987) with TLN that the backbone of the inhibitor binds via hydrogen bonds to the protein backbone of Trp115 as an antiparallel $\beta$-sheet. In this complex, the carbonyl oxygen of the benzyloxycarbonyl (Cbz) moiety of the inhibitor makes an efficient hydrogen bond (2.9 ̊) with the amide nitrogen of Trp115.

In the present complex with inhibitor (1), there is no enzyme-inhibitor interaction involving a Cbz moiety, but the free $\alpha$-amino group of (1) is hydrogen bonded via a water molecule to Trp115 NH in a similar way to the amide nitrogen
Table 2

Geometry around $\mathrm{Zn}^{2+}$ in the inhibitor (1)-TLN complex.

Angles $\left({ }^{\circ}\right)$.

\begin{tabular}{lr}
\hline His142 NE2-Zn-Inh O1P & 114.2 \\
His146 NE2-Zn-Inh O1P & 125.1 \\
Glu166 OE2-Zn-Inh O1P & 95.0 \\
His142 NE2-Zn-Inh O2P & 91.2 \\
His146 NE2-Zn-Inh O2P & 85.1 \\
Glu166 OE2-Zn-Inh O2P & 140.8 \\
\hline
\end{tabular}

Distances $(\AA)$.

Zn-His142 NE2 2.03

$\mathrm{Zn}-\mathrm{His} 146 \mathrm{NE2}-2.02$

Zn-Glu166 OE2

Zn-Inh O1P $\quad 1.90$

$\mathrm{Zn}-\mathrm{Inh} \mathrm{O} 2 \mathrm{P}$

of Gly in $\mathrm{ZG}^{\mathrm{P}} \mathrm{LA}\left(K_{i}=1.6 \times 10^{-8} M\right.$; Holden et al., 1987). The co-crystallization of (1) and TLN was achieved at $\mathrm{pH} 8$, supporting the presence of an unprotonated form of the free amino group.

The mode of recognition of the TLN active site by compound (1) is very similar to that described recently for compound (6) (Gaucher et al., 1999). Indeed, both compounds (i) occupy an extended domain encompassing the $S_{1}-S_{2}^{\prime}$ subsites, (ii) act as bidentate ligands of the catalytic $\mathrm{Zn}$ ion and (iii) satisfy the set of hydrogen bonds involving Arg203 and Asn112 as commonly found in TLN-inhibitor complexes (Matthews, 1988). Therefore, similar inhibitory potencies might be expected for both inhibitors. However, the phosphonic inhibitor (1) $\left(K_{i}=9.3 \times 10^{-7} M\right)$ is 50-fold less efficient than compound (6) $\left(K_{i}=2 \times 10^{-8} M\right)$ towards TLN. Several explanations could be proposed to account for this apparent discrepancy.

Firstly, there is no donor group in compound (1) that interacts with the carbonyl of Ala113, as observed in the complex of TLN with (6) (Gaucher et al., 1999). This interaction is very important in terms of the affinity constant as deduced from comparison between the $K_{i}$ values of $\mathrm{ZF}^{\mathrm{P}} \mathrm{LA}$ (5) $\left(K_{i}=6.8 \times 10^{-11} M\right)$ and $\mathrm{ZF}^{\mathrm{P}}(\mathrm{O}) \mathrm{LA}(4)\left(K_{i}=4.5 \times\right.$ $10^{-8} M$ ) towards TLN (Bartlett \& Marlowe, 1987).

Secondly, differences in solvation of the free and bound inhibitors (1) and (6) could also account for their respective inhibitory potencies. Furthermore, the presence of a $\mathrm{CH}_{2}$ group in the vicinity of the zinc-chelating phosphonic moiety provides a larger flexibility in (1) compared with (6) in solution. This could introduce an unfavourable entropic factor during the enzyme-recognition process in the case of (1). It is interesting to note that no head-to-tail hydrogen bonding was observed by NMR (not shown) for compound (1) in solution.

It cannot be excluded that the strength of zinc coordination by the thiol and oxygen groups in (6) is higher than the bidentate interaction of the phosphonic group in (1). This seems to be supported by the similarity in the $K_{i}$ values of (6) and (4), despite there being no binding to the $S_{2}$ subsite in (6).

TLN is currently taken as a model for zinc-metalloendopeptidases such as NEP, thus assuming a great similarity in the 
mechanism of action and active-site structures. This has been recently confirmed by computer modelling (Tiraboschi et al., 1999) and crystallographic analysis (Oefner et al., 2000).

A comparison of TLN and NEP inhibition is given in Fig. 4. The two active sites are superimposed with the $\mathrm{Zn}$ atom as a pivot and showing the two coordinated histidines (His142 and His146 for TLN; His583 and His587 for NEP) and the glutamic acid (Glu166 for TLN; Glu646 for NEP). The two inhibitors (1) (for TLN) and phosphoramidon (for NEP) are shown according to the $L S Q$ fits of their active sites. Although they show similar backbone conformations, orientations and coordination around the $\mathrm{Zn}$ atom, they display some differences as observed in the $S_{1}$ and $S_{2}^{\prime}$ subsites. Two immediate observations can be made: (i) the rhamnose moiety in the NEPphosphoramidon structure only makes a weak polar interaction through the ring oxygen (none of the hydroxyls O2, O3 or $\mathrm{O} 4$ are involved in interactions) and (ii) in the $\mathrm{S}_{2}^{\prime}$ subsite the aromatic ring moiety adopts a different stacking orientation.

Using these data, we need to explain why the protection of the free $\alpha$-amino group of (2) with a Cbz group in (3) only induces a threefold change in the $K_{i}$ value for NEP, but a 50 -fold change for TLN. This result could be interpreted as a difference in the $S_{1}-S_{2}$ domains of NEP compared with TLN. In the latter enzyme, the S2 subsite is significantly hydrophobic, as illustrated by the high potency of inhibitors wrapping the four $S_{2}, S_{1}, S_{1}^{\prime}$ and $S_{2}^{\prime}$ subsites with lipophilic side chains (compound 5).

In the case of NEP, as previously outlined, inhibition is essentially ensured by the $S_{1}^{\prime}$ and $S_{2}^{\prime}$ subsite occupancy: hence, thiorphan and its analogues (Roques et al., 1980; FourniéZaluski et al., 1984) inhibit NEP in the nanomolar range. Compounds containing side chains that are potentially able to recognize the $S_{1}-S_{2}$ domains are less efficient with regard to NEP inhibition (Mumford et al., 1982; Chen et al., 2000) and polar groups, such as the free amino group in (1), have no effect. This seems to indicate that the putative $S_{1}-S_{2}$ domain in NEP is freely accessible to the solvent and that there are no stabilizing interactions involving this part of the active site. This finding is supported by the large solvent accessibility of rhamnose moiety in the recently published crystalline structure of the phosphoramidon-NEP complex (Oefner et al., 2000).

\section{References}

Aubry, M., Bertheloot, A., Beaumont, A., Roques, B. P. \& Crine, P. (1987). Biochem. Cell Biol. 65, 398-404.

Bartlett, P. A. \& Marlowe, C. K. (1983). Biochemistry, 22, 4618-4624. Bartlett, P. A. \& Marlowe, C. K. (1987). Biochemistry, 26, 8553-8561.

Benchetrit, T., Fournié-Zaluski, M. C. \& Roques, B. P. (1987). Biochem. Biophys. Res. Commun. 147, 1034-1040.

Bode, W., Gomis-Rüth, F. X. \& Stöckler, W. (1993). FEBS Lett. 331, 134-140.

Bohacek, R., De Lombaert, S., McMartin, C., Priestle, J. \& Grütter, M. (1996). J. Am. Chem. Soc. 118, 8231-8249.

Brünger, A. T., Krukowski, A. \& Erickson, J. W. (1990). Acta Cryst. A46, 585-593.

Chen, H., Noble, F., Coric, P., Fournié-Zaluski, M. C. \& Roques, B. P. (1998). Proc. Natl Acad. Sci. USA, 95, 12028-12033.
Chen, H., Noble, F., Mothé, A., Meudal, H., Coric, P., Danascimento, S., Roques, B. P., George, P. \& Fournié-Zaluski, M. C. (2000). J. Med. Chem. 43, 1398-1408.

Collaborative Computational Project, Number 4 (1994). Acta Cryst. D50, 760-764.

Fourme, R., Dhez, P., Benoit, J. P., Kahn, R., Dubuisson, J. M., Besson, P. \& Frouin, J. (1992). Rev. Sci. Instrum. 63, 982-987.

Fournié-Zaluski, M. C., Soroca-Lucas, E., Waksman, G. \& Roques, B. P. (1984). Eur. J. Biochem. 139, 267-274.

Gaucher, J. F., Selkti, M., Tiraboschi, G., Prangé, T., Roques, B. P., Tomas, A. \& Fournié-Zaluski, M. C. (1999). Biochemistry, 38, 12569-12576.

Goudreau, N., Guis, C., Soleilhac, J. M. \& Roques, B. P. (1994). Anal. Biochem. 219, 87-95.

Hangauer, D. G., Monzingo, A. F. \& Matthews, B. W. (1984). Biochemistry, 23, 5730-5741.

Hanson, M. A. \& Stevens, R. C. (2000). Nature Struct. Biol. 7, 687692.

Holden, H. M., Tronrud, D. E., Monzingo, A. F., Weaver, L. H. \& Matthews, B. W. (1987). Biochemistry, 26, 8542-8553.

Jones, T. A., Zou, J. Y., Cowan, S. W. \& Kjeldgaard, M. (1991). Acta Cryst. A47, 110-119.

Kam, C. M., Nishino, N. \& Powers, J. C. (1979). Biochemistry, 18, 3032-3038.

Komiyama, T., Suda, H., Aoyagi, T., Takeuchi, T., Umezawa, H., Fujimoto, K. \& Umezawa, S. (1975). Arch. Biochem. Biophys. 171, 727-731.

Laskowski, R. A., MacArthur, M. W., Moss, D. S. \& Thornton, J. M. (1993). J. Appl. Cryst. 26, 283-291.

Leslie, A. G. W. (1990). Crystallographic Computing 5: From Chemistry to Biology, edited by D. Moras, A. D. Podjarny \& J. C. Thierry, pp. 60-61. Oxford University Press.

Luzzati, V. (1952). Acta Cryst. 5, 802-810.

Matthews, B. W. (1988). Acc. Chem. Res. 21, 333-340.

Matthews, B. W., Jansonius, J. N., Colman, P. M., Shoenborn, B. \& Dupourque, D. (1972). Nature New Biol. 238, 37-41.

Merritt, E. A. \& Bacon, D. J. (1997). Methods Enzymol. 277, 505-524.

Mumford, R. A., Zimmerman, M., ten Broeke, J., Taub, D., Joshua, H., Rothrock, J. W., Hirshfield, J. M., Springer, J. P. \& Patchett, A. A. (1982). Biochem. Biophys. Res. Commun. 109, 1303-1309.

Natesh, R., Schwager, S. L., Sturrock, E. D. \& Acharya, K. R. (2003). Nature (London), 421, 551-554.

Oefner, C., D’Arcy, A., Hennig, M., Winkler, F. K. \& Dale, G. E. (2000). J. Mol. Biol. 296, 341-349.

Roques, B. P., Fournié-Zaluski, M. C., Soroca, E., Lecomte, J. M., Malfroy, B., Llorens, C. \& Schwartz, J. C. (1980). Nature (London), 288, 286-288.

Sansom, C. E., Hoang, M. V. \& Turner, A. J. (1998). Protein Eng. 11, 1235-1241.

Schechter, I. \& Berger, A. (1967). Biochem. Biophys. Res. Commun. 27, 157-162.

Sheldrick, G. M. \& Schneider, T. R. (1997). Methods Enzymol. 277, 319-343.

Swaminathan, S. \& Eswaramoorthy, S. (2000). Nature Struct. Biol. 7, 693-699.

Thunnissen, M. M., Nordlund, P. \& Haeggström, J. Z. (2001). Nature Struct. Biol. 8, 131-135.

Tiraboschi, G., Jullian, N., Théry, V., Antonczak, S., Fournié-Zaluski, M. C. \& Roques, B. P. (1999). Protein Eng. 12, 141-149.

Tronrud, D. E., Holden, H. M. \& Matthews, B. W. (1987). Science, 235, 571-574.

Tronrud, D. E., Monzingo, A. F. \& Matthews, B. W. (1986). Eur. J. Biochem. 157, 261-268.

Umezawa, S., Tatsuta, K., Izawa, O. \& Tsuchiya, T. (1972). Tetrahedron Lett. 1, 97-100.

Weaver, L. H., Kester, W. R. \& Matthews, B. W. (1977). J. Mol. Biol. 114, 119-132. 